\title{
Alcohol and tobacco use and the diseases treated in general practice
}

\author{
Maria Flora de Almeida ${ }^{1}$, Filipe Fernandes Ferreira ${ }^{2}$, Mílton de Arruda Martins ${ }^{3}$, Mario Ferreira Junior ${ }^{4 *}$ \\ ${ }^{1} \mathrm{MD}$, Assistant Physician, Internal Medicine Service, Hospital das Clínicas da Faculdade de Medicina da Universidade de São Paulo (HC-FMUSP), São Paulo, SP, Brazil \\ ${ }^{2}$ Medical Student, FMUSP, São Paulo, SP, Brazil \\ ${ }^{3} \mathrm{MD}$, PhD, Full Professor of Internal Medicine, Department of Internal Medicine, FMUSP, São Paulo, SP, Brazi \\ ${ }^{4} \mathrm{MD}$, PhD, Assistant Physician, Internal Medicine Service, HC-FMUSP, São Paulo, SP, Brazil
}

Study conducted at the Outpatient General and Teaching Clinic (AGD) Internal Medicine Service, Department of Internal Medicine, Hospital das Clínicas da Faculdade de Medicina da Universidade de São Paulo (HC-FMUSP), São Paulo, SP, Brazil

Article received: 9/14/2016 Accepted for publication: 11/7/2016

*Correspondence: Address: Av. Dr. Enéas de Carvalho Aguiar, 455 São Paulo, SP - Brazil Postal code: 05403-000 mariofj@uol.com.br

http://dx.doi.org/10.1590/1806-9282.63.05.452

\section{SUMMARY}

Objective: To characterize the use of alcohol and tobacco and correlate both to the diseases of outpatients in a general practice outpatient clinic.

Method: The ASSIST (Alcohol, Smoking and Substance Involvement Screening Test) questionnaire was answered by 300 randomly chosen subjects assigned to different groups according to the diseases being treated at the Outpatient General and Teaching Clinic of the Department of Internal Medicine, Hospital das Clínicas of the University of São Paulo's School of Medicine (HC-FMUSP, in the Portuguese acronym), São Paulo, Brazil. The consumption of tobacco and alcohol was characterized and its correlation with the groups of diseases being treated was calculated using Chi-square and Pearson test statistics.

Results: Compared to alcohol, tobacco use was more prevalent, more intense and showed more health-, social-, legal- and financial-related damage. Tobacco smoking presented a positive significant $(\mathrm{p}<0.0001)$ correlation with respiratory diseases. According to the questionnaire's criteria, few alcohol users would be referred to clinical interventions in comparison to smokers.

Conclusion: Respiratory diseases and tobacco use were well correlated based on the ASSIST questionnaire. The preventive value of the questionnaire was more evident in relation to tobacco than alcohol consumption.

Keywords: alcohol abuse, tobacco use, screening, diagnosis.

\section{INTRODUCTION}

Diagnosing and treating alcohol, tobacco and other drug addictions early is critical to the prognosis of these disorders for patients and the society. It is estimated that about $20 \%$ of patients treated in the primary care network consume alcoholic beverages at levels that may endanger their health or be associated with diseases, signs or symptoms that lead them to seek treatment. ${ }^{1}$

Usually, the first contact of these patients with the health system occurs through general practitioners or family and community physicians, at the primary care level. However, studies have shown that these physicians do not diagnose or treat the harmful use of dependencecausing substances with the same frequency and precision that they would treat other chronic diseases. ${ }^{2}$ Regarding alcohol consumption and smoking, the most relevant dependence-causing substances in general clinical practice, the focus of medical professionals is on the diseases caused by such abuse, which manifest later (liver and pancreatic diseases, as well as nervous, respiratory, cardiac diseases, etc.), and not on the underlying dependence or abuse, by itself. ${ }^{2}$

It is well known that substance users do not become dependent overnight. The average period between the first consequence due to alcohol use and the first intervention for this problem is around five years, and any delay in initiating treatment, as well as any inadequate treatment, worsens the prognosis. As for tobacco, the latency period between the beginning of consumption and the first symptoms takes decades, as do the first initiatives to interrupt use. ${ }^{2}$

The World Health Organization (WHO) Expert Committee on Problems Related to Alcohol Consumption concluded that the first step to be taken to better address the problem is to screen or track abusive or problematic substance use. ${ }^{3,4}$ For this, it is necessary to use instruments with the function of pointing out, from a population sample or selected groups, people who consume these substances more intensely, with signs of abuse or complications resulting from these habits, and indicating intervention strategies. In the case of tobacco, the WHO 
Framework Convention on Tobacco Control recommends a wide range of measures of a political, economic, institutional and medical nature, in order to face the health complications related to smoking. ${ }^{5}$

In addition to other instruments (CAGE, ${ }^{6}$ AUDIT, ${ }^{7}$ the Fagerström test ${ }^{8}$ ), the ASSIST (Alcohol, Smoking and Substance Involvement Screening Test) ${ }^{9}$ is a questionnaire advocated by the WHO to simultaneously monitor the consumption of alcohol, tobacco, other drugs (marijuana, cocaine, crack, amphetamines, inhalants, opiates) and non-prescription addictive psychoactive drugs. It is an instrument of good sensitivity and good predictive value to detect the use and some consequences of these substances, already validated in Brazil. ${ }^{10}$

Its application in a general practice service, which serves patients whose complexity of clinical settings mixes the need for primary and secondary care, can be useful for the improvement of the services provided in the treatment of chronic diseases and for the establishment of prevention strategies ${ }^{11}$ aimed at the cessation, reduction or safe consumption of substances that are available to general practitioners and in accordance with national public policies.

The primary goal of our study was to screen and stratify, based on the ASSIST questionnaire, alcohol and tobacco consumption and some of their consequences among people seeking medical care in an outpatient clinic of a university hospital. Our secondary goal was to attempt to correlate such consumption with the diseases informed in the patients' electronic medical charts.

\section{Method}

The study was conducted at the facilities of the Outpatient General and Teaching Clinic (AGD), Internal Medicine Service, Department of Internal Medicine, Hospital das Clínicas of the University of São Paulo Medical School (HC-FMUSP, in the Portuguese acronym).

The AGD is sought by patients treated within the Brazilian public Unified Health System (SUS, in the Portuguese acronym) for internal medicine consultations, with diseases that fit into all clinical specialties. The internship in this service serves as training for fifth year students and resident physicians, in the first year of specialization in internal medicine at FMUSP. This is a short-term outpatient clinic (the average length of stay is six months), which, before patients are referred to other services, has the following main purposes: to diagnose and start treatment of clinical diseases at any level of complexity, to adjust the treatment of patients with multiple chronic diseases already known, and to promote screening, counseling and chemoprophylaxis for risk factors of diseases with high morbidity and mortality.
From February 1 to November 30, 2015, 300 patients, about $1 \%$ of all patients treated in the AGD during that period, were randomly approached by the researchers while waiting for their consultation in the waiting room of the outpatient clinic. Each patient was informed by then about the characteristics of the research and those who agreed to participate signed a Free and Informed Consent Form (FICF) approved by the Research Ethics Committee of HC-FMUSP, according to Resolution No. 196/96 (Opinion No. 858.978/14). Then, in the office, they answered questions from the ASSIST questionnaire, always asked by the researchers themselves.

The ASSIST questionnaire provides information on: a) use of alcohol, tobacco and other substances throughout life and in the past three months; b) signs of dependence, problems (health, social, legal or financial) and impairment of activities of daily living related to recent use (last three months); c) impact of consumption among relatives; d) old and recent cessation attempts. In addition, based on the progressive sum of scores attributed to each given response, the ASSIST questionnaire "suggests" the type of intervention required for each patient, that is: none, brief or advanced. ${ }^{9,10}$

The completed questionnaires were identified by the registration number of each patient in the service, so that the authorized researchers could have access to the demographic data and the diseases treated constantly in their electronic medical records. The diseases indicated in the medical records of the study participants were grouped according to their clinical nature as: cardiovascular, respiratory, liver and pancreatic, metabolic, autoimmune, psychiatric, oncological and miscellaneous. The same patient could fit into more than one group of diseases.

The collected data were stored and processed in spreadsheets using Statistical Package for the Social Sciences (SPSS) software version 11.0. All variables studied were categorized and described as absolute numbers and/ or percentages and, whenever necessary, allowed the investigation of correlations based on Chi-square method, using Pearson's test to quantify differences between groups. A level of $\mathrm{p}<0.05$ was used to define the significance of the correlations evaluated.

\section{RESULTS}

Of the 300 participants, 118 (39.3\%) were men between 16 and 92 years of age, with mean age (standard deviation) of 57.7 (15.2) years, while $182(60.7 \%)$ were women aged 14 to 85 years, with a mean age of 54.8 (14.9) years. There was no statistically significant difference between groups. 
Table 1 shows the distribution in absolute numbers of patients with the diseases reported in electronic medical charts, divided by sex and age group. This information was obtained for only 247 of the 300 participants. Statistically significant differences were observed with predominance of psychiatric (e.g., depression and anxiety) and autoimmune diseases (e.g., rheumatoid arthritis and lupus erythematosus) in women, and a higher prevalence of cardiovascular diseases (e.g., hypertension, coronary artery disease) and metabolic diseases (e.g., diabetes, dyslipidemia) in the elderly.

Alcohol and tobacco use in the study group, identified based on the answers given to the seven questions in the ASSIST questionnaire, is described in Table 2, as well as the total score range reached and the respective intervention suggestions, calculated according to the questionnaire-embedded criteria.

Overall, although less often tried compared with alcohol throughout life, there was a more prevalent and more intense consumption of tobacco and indications that it causes more craving and complications (health, social, legal or financial) for the patient, more concern for family and close friends, and more unsuccessful cessation attempts than alcohol in this AGD group.

Statistical tests to identify correlations between alcohol consumption, as reported in the ASSIST questionnaire, with demographic variables and the groups of diseases being treated in the AGD only indicated that men consume almost three times more alcoholic beverages than women $(\mathrm{p}=0.0001)$. No other significant correlation was found with the other variables.

Regarding tobacco consumption, no difference was detected in relation to sex, but a positive and significant correlation was observed between the sum of scores on the ASSIST questionnaire and reference to respiratory diseases in the medical charts $(\mathrm{p}=0.0001)$. All persons with scores in the range that would justify advanced smoking cessation intervention (sum of scores > 26) were already undergoing treatment for respiratory disease or attempted cessation in the AGD.

No significant correlation was found between the simultaneous consumption of alcohol and tobacco with any of the groups of diseases being treated.

\section{Discussion}

Consumption of alcohol and smoking are common habits in our culture. As they are associated with several diseases of high morbidity and early mortality, ${ }^{12-14}$ drinking and smoking are of particular interest to physicians, especially those who work in primary and secondary health care. Identifying individuals who present dependence, abuse or problems arising from these substances can allow more effective actions both at therapeutic and preventive level, although there are still few well organized initiatives in this regard. ${ }^{15}$

For instance, the WHO Expert Committee on Problems Related to Alcohol Consumption found that in most countries the number of people seeking or needing treatment is heterogeneous in relation to the severity of alcohol dependence and the physical and mental illnesses they present. ${ }^{3}$ The same committee concluded that evaluation and brief intervention in the context of primary health services prove effective in reducing heavy or more advanced alcohol-related problems in a variety of different sociocultural situations, but concluded that more research on the implementation of continuous strategies to address the issue in different health systems is required. ${ }^{16}$

As for tobacco, supported by laws that totally restrict smoking within public places ${ }^{17}$ and national and interna-

TABLE 1 Absolute number (N) of patients with diseases included in the respective morbidity groups, as informed in the electronic medical charts of the Outpatient General and Teaching Clinic of the Internal Medicine Service at HC-FMUSP, properly discriminated and compared by gender and age group ( $\mathrm{N}=247)$.

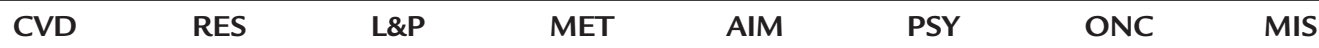

\begin{tabular}{|c|c|c|c|c|c|c|c|c|}
\hline & & & & $(\mathrm{N})$ & & & & \\
\hline Sex & & & & & $*$ & * & & \\
\hline M & 62 & 16 & 9 & 48 & 2 & 8 & 3 & 66 \\
\hline $\mathrm{F}$ & 93 & 19 & 8 & 78 & 14 & 35 & 5 & 112 \\
\hline Age range & * & & & * & & & & \\
\hline$\leq 30$ years & 2 & 2 & 0 & 3 & 2 & 2 & 0 & 10 \\
\hline 31 to 60 years & 70 & 14 & 10 & 62 & 9 & 25 & 3 & 88 \\
\hline$>60$ years & 83 & 19 & 7 & 61 & 5 & 16 & 5 & 80 \\
\hline
\end{tabular}

CVD: cardiovascular disease; RES: respiratory disease; L\&P: liver and pancreatic disease; MET: metabolic disease; AIM: autoimmune disease; PSY: psychiatric disease; ONC: oncological disease; MIS: miscellaneous.

* Statistically significant difference of the frequency of diseases of the respective group between the sexes or between the age groups ( $p<0.05)$, detected using Chi-square method and Pearson's test. 
TABLE 2 Alcohol and tobacco consumption identified in the ASSIST (Alcohol, Smoking and Substance Involvement Screening Test) questionnaire for the patients attended at the Outpatient General and Teaching Clinic of the Internal Medicine Service at HC-FMUSP ( $\mathrm{N}=300)$.

$\begin{array}{ll}\text { Alcohol } & \text { Tobacco } \\ \mathbf{n}(\%) & \text { n (\%) }\end{array}$

1. Have you ever used alcohol/tobacco?

$\begin{array}{lll}\text { No } & 41(13.7) & 89(24.7) \\ \text { Yes } & 259(86.3) & 211(70.3)\end{array}$

2. How often have you used it in the past 3 months?

\begin{tabular}{lll} 
Never & $182(71.6)$ & $138(65.4)$ \\
\hline Once or twice & $23(9.0)$ & $2(0.9)$ \\
\hline Monthly & $15(5.9)$ & $3(1.4)$ \\
\hline Weekly & $29(11.4)$ & $4(1.9)$ \\
Daily or almost daily & $6(2.4)$ & $64(30.3)$
\end{tabular}

In the last three months (questions 3 to 5 ):

3. How often you had a strong desire or urge to use?

\begin{tabular}{lll}
\hline Never & $238(95.8 \%)$ & $144(68.2)$ \\
\hline Once or twice & $3(1.2)$ & $2(0.9)$ \\
\hline Monthly & $1(0.4)$ & $2(0.9)$ \\
\hline Weekly & $3(1.2)$ & $2(0.9)$ \\
\hline Daily or almost daily & $4(1.6)$ & $61(28.4)$ \\
\hline How often has drinking/smoking led to health, social, legal, or financial problems? & $247(99.6)$ & $189(89.5)$ \\
\hline Never & $0(0.0)$ & $4(1.9)$ \\
\hline Once or twice & $0(0.0)$ & $1(0.5)$ \\
\hline Monthly & $0(0.0)$ & $2(0.9)$ \\
\hline Weekly & $1(0.4)$ & $15(7.1)$
\end{tabular}

5. How often have you failed to do what was normally expected of you because of your drinking/smoking habit?

\begin{tabular}{|c|c|c|}
\hline Never & $244(98.4)$ & $193(91.9)$ \\
\hline Once or twice & $2(0.8)$ & 7 (3.3.) \\
\hline Monthly & $1(0.4)$ & $3(1.4)$ \\
\hline Weekly & $1(0.4)$ & $5(2.4)$ \\
\hline Daily or almost daily & $0(0.0)$ & $2(1.0)$ \\
\hline \multicolumn{3}{|c|}{ 6. Has a friend or relative or anyone else ever expressed concern about your drinking or smoking? } \\
\hline No & $186(75.6)$ & $84(40.8)$ \\
\hline Yes, but not in the last 3 months & $49(19.9)$ & $71(34.5)$ \\
\hline Yes, in the last 3 months & $11(4.5)$ & $52(24.8)$ \\
\hline \multicolumn{3}{|c|}{ 7. Have you ever tried to control, cut down or stop using alcohol/tobacco? } \\
\hline No & $223(91.0)$ & $108(52.7)$ \\
\hline Yes, but not in the last 3 months & $17(6.9)$ & $62(30.2)$ \\
\hline Yes, in the last 3 months & $5(2.0)$ & $35(17.1)$ \\
\hline \multicolumn{3}{|c|}{ Suggested intervention according to the ASSIST questionnaire score } \\
\hline None & $293(97.7)$ & $191(63.7)$ \\
\hline Brief & $5(1.7)$ & $95(31.6)$ \\
\hline Advanced & $2(0.7)$ & $14(4.7)$ \\
\hline
\end{tabular}


tional policies that encourage smoking reduction through collective and individual measures, including facilitating access to treatment drugs, programs in the area of health, organized and coordinated by entities of national and regional weight, such as the Brazilian National Cancer Institute (Inca, in the Portuguese acronym) and state and municipal health departments have multiplied in recent years. The purpose of these programs is to train health professionals, especially those in primary care, to give sufficient and necessary support to smokers who express their desire to stop smoking, regardless of whether or not they have a related disease that is already manifest. ${ }^{18}$ It is true that the interest in such actions in the health area varies according to the context and type of medical care offered.

In our study, the WHO ASSIST questionnaire was applied to a group of AGD patients, a general practice outpatient clinic that, although located in a university hospital with characteristics of tertiary care, due to its teaching nature, also treats patients whose disease complexity is variable (primary, secondary or tertiary), including those potentially associated with the consumption of substances that are harmful to health. For the purposes of our study, and based on the demographic profile of the studied population, with an average age above 50 years, only alcohol and tobacco were considered, although the research instrument allows to approach the use of other drugs and psychoactive substances without medical prescription.

The randomly chosen sample represented the public that seeks the AGD, composed preferably by women in the age group between 55 and 60 years. Table 1 indicates the number of patients with diseases belonging to the eight groups in the study, with a clear predominance of cardiovascular and metabolic diseases and a set of other less specific conditions, grouped as miscellaneous. Data analysis showed a statistically significant predominance of autoimmune and psychiatric diseases in women and of cardiovascular and metabolic diseases in older individuals, all known and plausible associations from a clinical-epidemiological point of view.

The analysis of the results obtained from the answers given to the ASSIST questionnaire shows that more individuals have tried alcoholic beverages $(86.3 \%)$ than tobacco $(70.3 \%)$ throughout their lives, but among those who continued to use them, in the last three months, smoking was a habit with characteristics of almost daily consumption (30.3\%), whereas alcohol was consumed in a more variable way, with only a minority $(2.4 \%)$ referring daily or almost daily consumption.

Unlike smoking, for which there is no known safe limit of consumption, and whose health complications occur with daily and old habits, in the case of alcoholic beverages, not only there is a risk of diseases resulting from persistent and excessive consumption, but also occasional abuse (which can be detected by the ASSIST) puts the consumer at risk of accidents, violence and infectious and sexually transmitted diseases. This reinforces the importance of detecting cases of excessive consumption, even occasionally, in order to be able to take preventive action. On the other hand, it is worth mentioning that scientific evidence indicates that the consumption of alcoholic beverages, controlled and in small amount daily, can be a protective factor for cardiovascular diseases ${ }^{19}$ indicating that drinking every day is not by itself an indicator of abuse or alcoholism.

In addition to the regularity of consumption, the questionnaire revealed that persistent smokers in the last three months reported more problems associated with dependence, health, social, legal and financial issues, as well as their daily activities than consumers of alcoholic beverages. The prevalence of cravings due to lack of nicotine (ASSIST question 3), if compared to lack of alcohol, can be explained by the fact that nicotine causes strong chemical dependence and also because the detected number of daily tobacco users was much higher than that of alcohol consumers in this sample. Although smoking may have a direct causal relation with the other problems identified in the ASSIST questions 4 and 5 (health, social, legal and financial complications, as well as daily activities), it is possible that this is a two-way relation, because stressful situations, such as those cited, are known triggers of the will to smoke.

The questionnaire also revealed that cigarette smoking was a major concern among relatives and friends of the research participants, who tried more often to unsuccessfully quit this habit compared to drinkers. The information obtained from the ASSIST questionnaire may indicate a fairly accurate notion of the participants, and of those close in their lives, regarding the risks of very frequent consumption of a chemical substance.

Based on the scores attributed to the answers given to questions 1 to 7 of the ASSIST questionnaire, seven patients (2.4\%) were referred for some type of intervention to stop drinking and 109 patients (36.3\%) were referred for brief or advanced programs aimed at quitting smoking. It should be noted that the marked disproportion between the two may be due to the age range of the participants studied, with a tendency to consume less alcohol than younger individuals, but also, and especially, due to differences in the criteria adopted in the ASSIST questionnaire to suggest interventions to patients. That is, in comparison 
with alcohol, a brief intervention is indicated for a sum of scores from 11 to 26 , whereas for tobacco, the same level of intervention is indicated for scores from 3 to 26, which shows much less tolerance for tobacco than alcoholic beverages, probably resulting in a referral of the most serious cases related to drinking, but less likely to act preventively, for example in cases of excessive consumption.

Last, tobacco and respiratory diseases were responsible for the only statistically significant positive correlation found between drinking or smoking habits with the diseases indicated in the patients' electronic medical charts. All individuals with respiratory diseases $(\mathrm{N}=35)$ were included among the 109 who received some type of intervention to quit smoking. These data indicate that the ASSIST questionnaire seems to be an instrument capable of detecting and discriminating people who require brief or advanced interventions to interrupt tobacco use, even before health complications appear, thus highlighting their preventive potential.

\section{Conclusion}

Applying the ASSIST questionnaire made it possible to adequately identify and stratify alcohol and cigarette users with more recent and more frequent consumption, as well as with more complications resulting from them, and, based on this, indicate brief or advanced interventions in a very careful manner, taking into account the peculiarities of the dependence caused by each of the evaluated habits. Regarding alcohol, the ASSIST questionnaire applied in an internal medicine outpatient clinic served to direct the intervention only to people with very high scores, suggesting that the main goal of the instrument is to promote the treatment of consumers with more general complications, whereas in the case of tobacco, the criterion was more preventive, suggesting interventions even for people with lower scores. In addition, all patients with respiratory diseases in which tobacco may be the cause or an aggravating factor were submitted to brief or advanced intervention, which did not occur with alcohol in relation to liver and pancreatic diseases.

\section{Resumo}

Uso de álcool e tabaco e as doenças tratadas em ambulatório de clínica geral

Objetivo: Caracterizar o consumo de álcool e tabaco e correlacioná-lo às doenças em tratamento de pacientes de um ambulatório de clínica geral.

Método: As perguntas do ASSIST (Alcohol, Smoking and Substance Involvement Screening Test) foram respondi- das por 300 pacientes escolhidos aleatoriamente e enquadrados em grupos conforme os diagnósticos das doenças em tratamento no Ambulatório Geral e Didático (AGD), Serviço de Clínica Geral do HC-FMUSP; o consumo das substâncias foi caracterizado e a sua correlação com as doenças em tratamento foi calculada por meio do método do Qui-quadrado e teste de Pearson.

Resultados: $\mathrm{O}$ consumo de tabaco mostrou-se mais prevalente, mais intenso e maior causa de complicações (de saúde, sociais, legais ou financeiras) do que o do álcool; o consumo de tabaco apresentou correlação positiva e significante $(\mathrm{p}<0,0001)$ com a referência de doença respiratória no prontuário médico. De acordo com o critério proposto no questionário, poucos consumidores de bebida alcoólica seriam encaminhados para intervenção preventiva, ao contrário do que ocorreria com os fumantes.

Conclusão: A aplicação do ASSIST permitiu caracterizar e correlacionar positivamente o uso de tabaco com doenças respiratórias em tratamento. A importância do questionário como instrumento preventivo das consequências do tabagismo ficou mais evidente do que em relação às associadas ao consumo de bebida alcoólica.

Palavras-chave: abuso de álcool, uso de tabaco, rastreamento, diagnóstico.

\section{References}

1. World Health Organization - WHO. Global Status Report on Alcohol. 2004. Available from: http://www.who.int/substance_abuse/publications/global_ status_report_2004_overview.pdf?ua $=1$

2. Brasil. Secretaria Nacional de Políticas sobre Drogas - SENAD. Curso SUPERA: Sistema para detecção do uso abusivo e dependência de substâncias psicoativas, encaminhamento, intervenção breve, reinserção social e acompanhamento. Available from: http://www.supera.senad.gov.br/.

3. World Health Organization - WHO. Management of Substance Abuse: WHO Expert Committee on Problems Related to Alcohol Consumption, Second Report. 2007. Available from: http://www.who.int/substance_abuse/ expert_committee_alcohol/en/.

4. United States Preventive Services Task Force - USPSTF. Screening and Behavioral Counseling Interventions to Reduce Alcohol Misuse. 2013. Available from: www.uspreventiveservicestaskforce.org/uspstf/uspsdrin.htm.

5. World Health Organization - WHO. WHO Framework Convention on Tobacco Control. Available from: http://www.who.int/fctc/en/.

6. Steinweg DL, Worth H. Alcoholism: the keys to the CAGE. Am J Med. 1993; 94(5):520-3.

7. World Health Organization - WHO. AUDIT - The Alcohol Use Disorders Identification Test: Guidelines for use in primary care. 2001. 2. ed. Available from: http://apps.who.int/iris/bitstream/10665/67205/1/WHO_MSD_ MSB_01.6a.pdf.

8. Heatherton TF, Kozlowski LT, Frecker RC, Fagerström K. The Fagerström Test for Nicotine Dependence: a revision of the Fagerström Tolerance Questionnaire. Br J Addict. 1991; 86:11(9)19-27.

9. World Health Organization - WHO. Alcohol, Smoking and Substance Involvement Screening Test - ASSIST. Available from: www.who.int/ substance_abuse/activities/assist_portuguese.pdf?ua $=1$

10. Silva-Henrique IF, Micheli D, Lacerda RB, Lacerda LA, Formigoni MLOS. Validação da versão brasileira do teste de triagem do envolvimento com álcool, cigarro e outras substâncias (ASSIST). Rev Assoc Med Bras. 2004; 50(2):199-206. 
11. National Institute on Drug Abuse - NIDA. DrugFacts: lessons from prevention research. Available from: www.drugabuse.gov/publications/ drugfacts/lessons-prevention-research.

12. Silva CJ, Castro LAPG, Laranjeira R. Diagnóstico e tratamento da dependência e uso nocivo de álcool. Unidade de Pesquisa em Álcool e Drogas (UNIAD) do Departamento de Psiquiatria da Universidade Federal de São Paulo; 2006.

13. Gigliotti A, Bessa MA. Alcohol dependence syndrome: diagnostic criteria. Rev Bras Psiquiatr. 2004; 26(suppl.1):11-3.

14. Centers for Disease Control and Prevention - CDC. Health effects of cigarette smoking. Available from: https://www.cdc.gov/tobacco/data_statistics/fact_ sheets/health_effects/effects_cig_smoking/

15. World Health Organization - WHO. Global Status Report: alcohol policy. Available from: http://www.who.int/substance_abuse/publications/en/ Alcohol Policy Report.pdf?ua=1
16. World Health Organization - WHO. Brief Intervention for Hazardous and Harmful Drinking: A manual for use in primary care. 2001. Available from: http://apps.who.int/iris/bitstream/10665/67210/1/WHO_MSD_ MSB 01.6b.pdf.

17. Brasil. Artigo 49 da Lei 12546 de 14/12/2011. Diário Oficial da União 15/12/2011, Seção 1, p. 3. Available from: http://www2.camara.leg.br/legin/ fed/lei/2011/lei-12546-14-dezembro-2011-612002-publicacaooriginal-134621pl.html

18. Brasil. Instituto Nacional de Câncer José de Alencar Gomes da Silva - INCA Programa Nacional de Controle do Tabagismo. Available from: http://www2. inca.gov.br/wps/wcm/connect/acoes_programas/site/home/nobrasil/ programa-nacional-controle-tabagismo/tratamento-do-tabagismo.

19. Fernández-Solà J. Cardiovascular risks and benefits of moderate and heavy alcohol consumption. Nat Rev Cardiol. 2015; 12(10):576-87. 